\title{
Anthropometric measurements- a study on options for identification of small babies in need of extra care
}

\author{
P. Sudhapriya ${ }^{1}$, Rinu Dwivedi ${ }^{2}$, Anushadipti ${ }^{3}$, Sarma K.V.S. ${ }^{4}$
}

${ }^{1}$ Dr. P. Sudha Priya, Assistant Professor, Department of Pediatrics, SPMC (W), SVIMS, Tirupati (A.P.), India, ${ }^{2}$ Dr. Rinu Dwivedi, Assistant Professor, Department of Pediatrics, SPMC (W), SVIMS, Tirupati (A.P.), India, ${ }^{3}$ Dr. Anushadipti, Assistant Professor, Department of Pediatrics, Asram Medical College, Eluru (A.P.), India, ${ }^{4}$ Prof K.V.S. Sarma, Biostatistician, SVIMS, Tirupati, India.

Corresponding Author: Dr. Rinu dwivedi, Assistant professor, Pediatrics, Sri Padmavathi Medical College for Women, Sri Venkateswara, Institute of Medical Sciences (SVIMS), Alipiri Road, Tirupati, (A.P.) India. Email-

dwivedirinu10@gmail.com

\begin{abstract}
Introduction: A large number of babies born in India and many developing countries are born at home and majority of them have no access to scales or other means by which they can be identified as LBW. The aim of our study was to determine the correlation of chest circumference and foot length with birth weight and gestational age and to determine the most sensitive and specific cut-off values for detection of Low birth weight and preterm babies using foot length and chest circumference. Methods: This was a prospective observational study done at a tertiary care centre in south India. We analyzed 1000 newborn babies within 24 hours of birth. For each baby we measured 1. chest circumference (CHC), 2. Foot length (FL), 3. Weight (BW) and 4. Gestational age (GA). Babies were classified according to GA (preterm/term) and BW (kg) as Very Low Birth Weight (VLBW) $(<1.5 \mathrm{~kg})$, Low Birth Weight (LBW) $(1.5-2.5 \mathrm{~kg})$ and Normal Birth Weight (NBW) ( $>2.5 \mathrm{~kg}$ ). Results: Significant positive correlation of 0.921 was found between FL and BW $(\mathrm{p}<0.001)$. The two ROC curves for FL and CHC were close to each with AUC 0.982 and 0.969 respectively and difference in the areas was statistically significant $(\mathrm{Z}=4.303, \mathrm{p}<0.0001)$ which suggested that FL was better indicator of BW. FL $<=6.4 \mathrm{~cm}$ predicts VLBW; between $6.4 \mathrm{~cm}$ and $7.3 \mathrm{~cm}$ predicts $\mathrm{LBW}$ and $>7.3 \mathrm{~cm}$ predicts NBW. For estimating preterm birth FL cut off was $<=7.1 \mathrm{~cm}$. Conclusion: FL and CHC both can be used as predictor for BW and GA estimation and FL was more appropriate than CHC considering its ease of measurement also. Screening of babies who are in need of extra care can be done using our cut off values and this can help in reducing neonatal mortality by early referrals.
\end{abstract}

Keywords: Chest circumference, Foot length, Preterm, LBW-low birth weight, NBW- normal birth weight, NICUneonatal intensive care unit, VLBW-very low birth weight.

\section{Introduction}

Globally, the main direct causes of neonatal deaths are estimated to be preterm birth $(28 \%)$, severe infections (26\%), and asphyxia (23\%). Low birth weight (LBW) is an important indirect cause of death [1]. Birth weight is the single most important predictor of neonatal mortality in developing countries.

About 0.75 million neonates die every year in India, the highest for any country in the world. However, the neonatal mortality rate (NMR) has declined from 52 per 1000 live births in 1990 to 28 per 1000 live births in

Manuscript received: $8^{\text {th }}$ January 2019

Reviewed: $18^{\text {th }}$ January 2019

Author Corrected: $25^{\text {th }}$ January 2019

Accepted for Publication: 31 $1^{\text {st }}$ January 2019
2013 but still preterm birth/LBW complications $(43.7 \%)$ are the leading cause of neonatal mortality followed by infections $(20.8 \%)$ and intrapartum related $(19.2 \%)$ complication [2]. Low birth weight is associated with high risk of infections, difficult breathing, hypothermia and feeding problems.

A large number of all babies born in India and many developing countries are born at home and the majority of communities have no access to weighing scales by which the baby can be identified as low birth weight which might need extra care at home or referral to NICU. It is important to identify these high-risk babies in order to prevent neonatal deaths. Deaths could be 


\section{Original Research Article}

reduced with low cost interventions that focus on keeping the baby warm, hygiene, breast feeding support, early identification and management of illness in the first days and weeks of life $[3,4]$.

Therefore, efforts have been made to identify more easily measured anthropometric surrogates for birth weight which are low cost and usable by community health workers.

Six separate research studies from UK, India, Nepal and Taiwan have reported that newborn foot length can be used as a screening tool for small babies however their cut-off points varied for different contexts and geographical areas [5-10].

There is therefore need for a study to identify the most appropriate anthropometric surrogate for LBW and its cut-off in Indian population.

The aim of our study is to determine the correlation of chest circumference and foot length with birth weight and gestational age and to determine the most sensitive and specific cut-off values for detection of low birth weight and preterm babies using these parameters.

\section{Material and Methods}

Study type- Prospective observational study

Place of study -tertiary care hospital, Tirupati (A.P.)

Inclusion criteria- All the babies born in our hospital and those coming for care to Paediatric department within $24 \mathrm{hrs}$ of life were included in the study.

Exclusion criteria- Babies with poor health conditions, which were in need of emergency care and those with congenital malformations, were excluded from the study.

Sample collection- We analysed 1000 newborn babies from May 2017 to May 2018. Informed written consent was obtained from the mothers and relatives before their babies were measured. For each recruited baby, the following measurements were done within 24 hours after birth.
1.Chest circumference (CHC) - at the level of xiphisternum with a standard measuring tape (COW HEAD BRAND).

2. Foot length (FL) - taken from heel to great toe of right foot with a transparent plastic ruler.

3. Weight (BW) of all babies was done in kilograms using digital weighing machine.

4. Gestation was analysed using new ballard score as preterm ( $<37$ weeks) and full term ( $>37$ weeks) [24]. All measurements were done with appropriate aseptic precautions.

The measurements were done in centimetre to one decimal place. The measurements were done by two trained doctors separately for each child and average of two readings was written as final value.

Ethical approval was taken from institutional ethical committee.

Data was entered in prescribed format. All the 1000 new born babies were classified according to gestation period (pre-term/term) and birth weight $(\mathrm{kg})$ viz., Very Low Birth Weight (VLBW) $(<1.5 \mathrm{~kg})$, Low Birth Weight (LBW) (1.5-2.5kg) and Normal Birth Weight (NBW) $(>2.5 \mathrm{~kg})$.

Statistical analysis-Data on FL, CHC and BW was summarized as mean and standard deviation (SD) in the three BW groups and compared by one-way Analysis of Variance (ANOVA). The correlation of FL with CHC and $\mathrm{BW}$ was found to examine the strength of linear relationship among these variables.

The functional relationship between BW and FL was obtained using linear regression. ROC curve analysis was used to find the optimal cutoff on FL and CHC, sensitivity, specificity, Area under the Curve (AUC) and the Likelihood Ratio (LR). Results with $\mathrm{p}<0.05$ were considered as significant. All the computations were carried out using IBM SPSS version 20.0 and ROC curve analysis was done using MedCalc version 15.0 .

\section{Results}

Among the 1000 babies in our study 597 were male $(\mathrm{M})$ and 403 were female $(\mathrm{F})$ while 303 were pre-term and 697 were term. 632 babies were NBW (BW >2.5kg), 274 were LBW $(1.5-2.5 \mathrm{~kg})$ and 94 were VLBW $(<1.5 \mathrm{~kg})$. No significant association was found between gestational age and gender of the baby ( $\mathrm{p}=0.334$ by Chi Square test). Table- 1 shows the category wise summary of FL, CHC and BW. 
Table-1: Summary statistics of different measurements.

\begin{tabular}{|c|c|c|c|c|c|c|}
\hline \multirow{2}{*}{$\begin{array}{l}\text { Measure- } \\
\text { ment }\end{array}$} & \multirow{2}{*}{$\begin{array}{c}\text { Range } \\
(M i n-M a x)\end{array}$} & \multirow{2}{*}{$\begin{array}{l}\text { All babies } \\
(n=1000)\end{array}$} & \multicolumn{3}{|c|}{ Mean \pm Standard Deviation } & \multirow[b]{2}{*}{ p-value* } \\
\hline & & & $\begin{array}{l}\text { VLBW } \\
(n=94)\end{array}$ & $\begin{array}{c}\text { LBW } \\
(n=274)\end{array}$ & $\begin{array}{c}\text { NBW } \\
(n=632)\end{array}$ & \\
\hline $\mathrm{FL}$ & $(4.30-8.60)$ & $7.39 \pm 0.73$ & $5.93 \pm 0.48^{a}$ & $6.88 \pm 0.28^{b}$ & $7.82 \pm 0.39$ & $<0.001$ \\
\hline $\mathrm{CHC}$ & $(19.0-39.00)$ & $29.73 \pm 3.50$ & $22.84 \pm 1.86^{\mathrm{a}}$ & $27.44 \pm 2.15^{b}$ & $31.75 \pm 1.88$ & $<0.001$ \\
\hline BW & $(0.65-4.50)$ & $2.54 \pm 0.69$ & $1.18 \pm 0.18^{\mathrm{a}}$ & $2.04 \pm 0.30^{\mathrm{b}}$ & $2.96 \pm 0.37$ & $<0.001$ \\
\hline
\end{tabular}

Significant positive correlation of 0.921 was found between FL and BW ( $<<0.001$ ). CHC and BW also had a significant positive correlation of $0.921(\mathrm{p}<0.001)$. The scatter diagrams in Figure-1 shows the nature of relationship between the measurements.

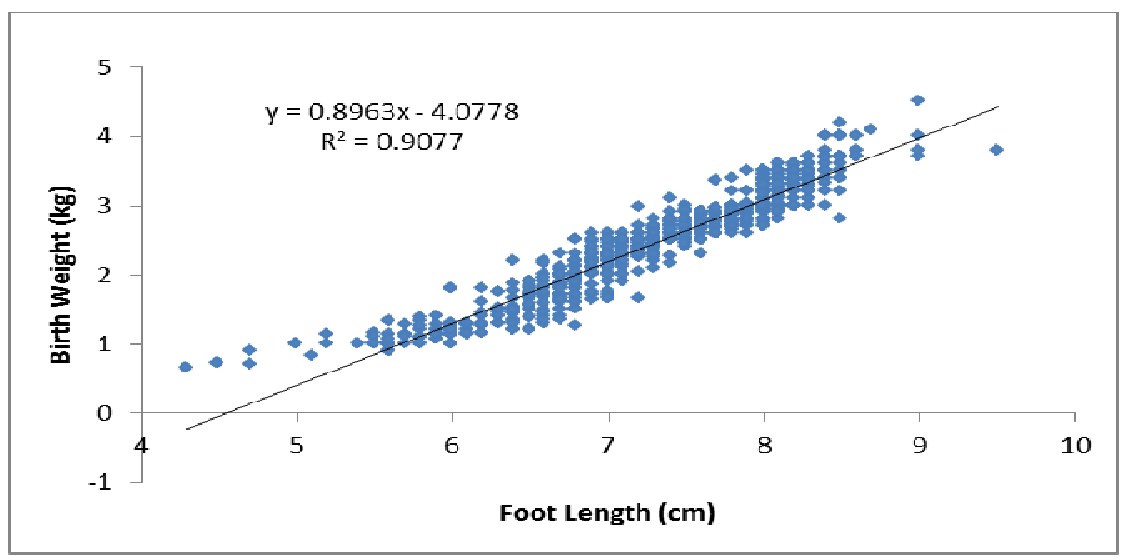

Figure-1: Scatter chart showing the relation between birth weight and foot length. BW versus FL

Linear regression of $\mathrm{BW}$ on FL was given as $\mathrm{BW}=-4.08+0.89 * \mathrm{FL}$ and the model has $\mathrm{R}^{2}=0.908$ ( $\left.\mathrm{p}<0.001\right)$. It means $90 \%$ of BW can be predicted by this formula using FL. The change in BW due to one cm change in FL was $0.89 \mathrm{~kg}$.

\section{Optimal cutoff and sensitivity of FL}

The utility of FL as a surrogate marker to distinguish between normal and low birth weight babies was carried out by using Receiver Operating Characteristic (ROC) curve analysis taking only two categories NBW and LBW (including VLBW).

Table-2: Optimal Cutoff and sensitivity statistics.

\begin{tabular}{|c|c|c|c|c|c|c|c|c|c|}
\hline Measurement & Cutoff & LBW & NBW & $\begin{array}{c}\text { AUC } \\
(95 \% \mathrm{CI})\end{array}$ & Sn (\%) & Sp (\%) & $+L R$ & -LR & $\begin{array}{l}\text { Odds } \\
\text { Ratio }\end{array}$ \\
\hline \multirow{2}{*}{ FL } & $<=7.3$ & 360 & 76 & \multirow{2}{*}{$\begin{array}{c}0.982 \\
{[0.96-0.988]}\end{array}$} & \multirow[t]{2}{*}{97.83} & \multirow[t]{2}{*}{87.97} & \multirow[t]{2}{*}{8.14} & \multirow[t]{2}{*}{0.025} & \multirow[t]{2}{*}{325.6} \\
\hline & $>7.3$ & 8 & 556 & & & & & & \\
\hline \multirow{2}{*}{$\mathrm{CHC}$} & $<=28.5$ & 307 & 20 & \multirow{2}{*}{$\begin{array}{c}0.969 \\
{[0.96-0.978]}\end{array}$} & \multirow[t]{2}{*}{83.42} & \multirow[t]{2}{*}{96.84} & \multirow[t]{2}{*}{26.4} & \multirow[t]{2}{*}{0.17} & \multirow[t]{2}{*}{155.3} \\
\hline & $>28.5$ & 61 & 612 & & & & & & \\
\hline
\end{tabular}

Since FL with cutoff $<=7.3 \mathrm{~cm}$ has higher AUC than that of $\mathrm{CHC}$ it is a better marker for predicting birth weight. Further it can detect $97.8 \%$ of true low birth babies. Further the $+\mathrm{LR}=8.14$ suggests that babies with FL $<=7.3$ were 8 times more likely to be LBW than those with FL $>7.3$ (Table 2). On the other hand, CHC $<=28.5 \mathrm{~cm}$ had a sensitivity of only $83.4 \%$ which means $16.6 \%$ low birth babies would go undetected by this screening. Hence FL is better than CHC. The ROC curves to predict BW using CHC and FL as surrogate marker is shown in Figure-2. 


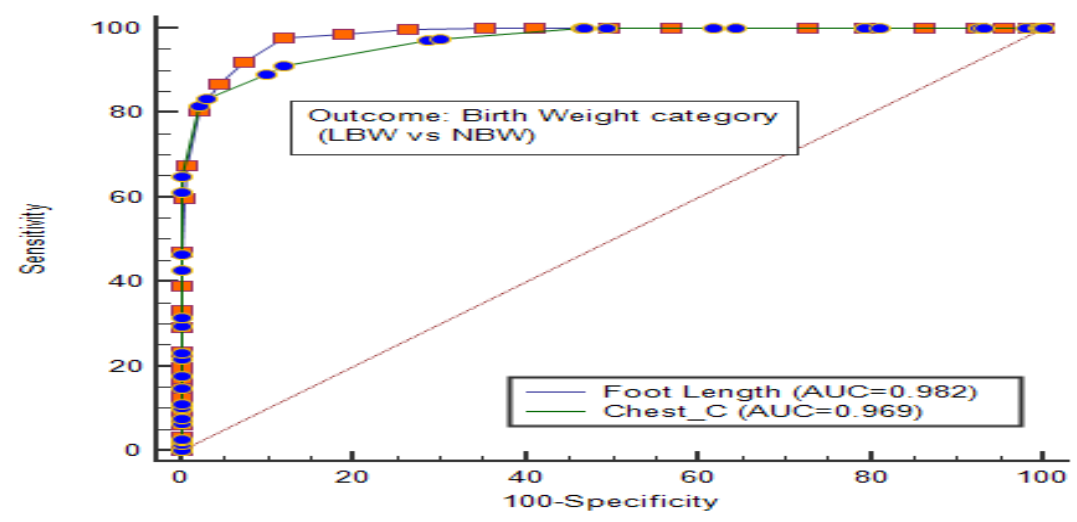

Figure-2: Comparison of ROC curves

The two ROC curves were close to each with AUC 0.982 and 0.969 for FL and CHC respectively. However the difference in the areas was statistically significant $(Z=4.303, p<0.0001)$ suggesting that FL was better marker of $B W$.

Among the 632 babies who were $<2.5 \mathrm{Kg}$, we determined the cutoff value on FL to distinguish between VLBW $(<1.5 \mathrm{Kg})$ and LBW $(1.5-2.5 \mathrm{Kg})$ using ROC curve analysis. The cut off was FL $<=6.4 \mathrm{~cm}$ with sensitivity of $89.4 \%$ and specificity of $91.2 \%$ and AUC 0.972. The positive and negative LRs are 10.2 and 0.12 respectively. The estimated prevalence of VLBW among the LBW babies was $25.5 \%$. The positive LR indicates that babies with FL $<=6.4 \mathrm{~cm}$ have 10 times more odds (likelihood) of becoming VLBW than those above $6.4 \mathrm{~cm}$.

Hence, $\mathrm{FL}<=6.4 \mathrm{~cm}$ predicts VLBW; between $6.4 \mathrm{~cm}$ and $7.3 \mathrm{~cm}$ predicts $\mathrm{LBW}$ and $>7.3 \mathrm{~cm}$ predicts NBW.

FL as a marker to predict gestation- The mean FL in the pre-term babies was $6.56 \mathrm{~cm}(\mathrm{SD}=0.57)$ while the babies delivered on completing the term it was $7.74 \mathrm{~cm}(\mathrm{SD}=0.45)$ and the difference was significant $(\mathrm{t}=35.2$, $\mathrm{p}<0.0001)$. So, FL could also be a surrogate marker to predict pre-term delivery. The optimal cutoff was FL $<=7.1 \mathrm{~cm}$ to classify as Preterm. ROC curve analysis shows AUC $=0.962$ with $91 \%$ sensitivity and $90 \%$ specificity as shown in Figure-3.

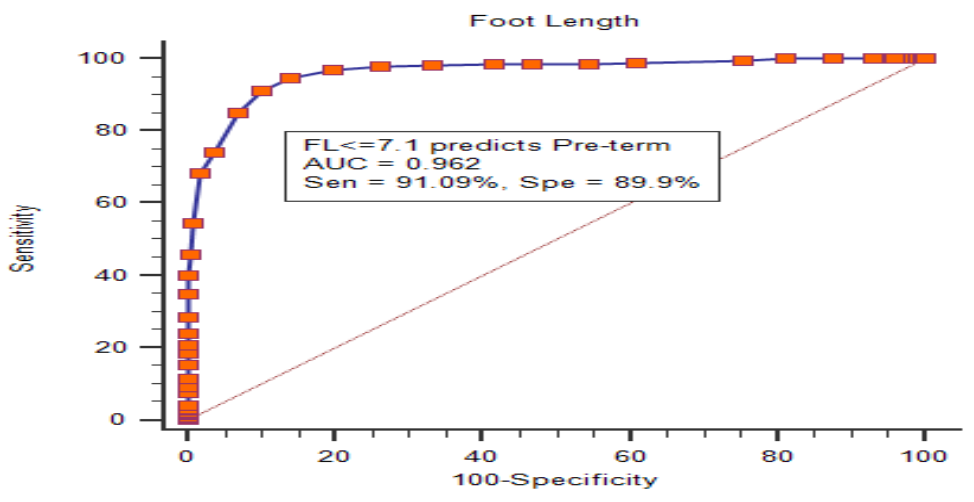

Figure-3: ROC curve to predict gestation.

\section{Discussion}

Many previous studies showed that the anthropometric measurements like Head circumference, Chest circumference, Thigh circumference and Mid upper arm circumference and foot length can be used as a predictor of LBW. Most of these studies concluded that foot length and chest circumference were better predictors of birth weight as compared to other measures but cut offs were different based on geographical area of study $[11,12,13]$.
Vishnu Datt Pandey et al concluded that even foetal foot length was a good marker for gestational age using ultrasonography especially in cases of femur achondroplasia, dolichocephaly or brachycephaly and in cases where mothers were not sure about their last menstrual period [14]. Two other studies supported these findings $[15,16]$. Hence we analysed only foot length and chest circumference and found cut off values for predicting birth weight and gestational age. 
Kulkarni et al. found that $42.3 \%$ babies were below $2500 \mathrm{~g}$ and $12.3 \%$ below $2000 \mathrm{~g}$ whereas in the present study, $36.8 \%$ were $<2.5 \mathrm{~kg}$ and $9.4 \%$ were $<1.5 \mathrm{~kg}$ [17].

Elizabeth et al. (2013) studied706 newborns and measured their foot length, head, chest, thigh and midupper arm circumferences. Foot length had the highest predictive value for low birth weight $(\mathrm{AUC}=0.97)$ followed by mid-upper arm circumference (AUC $=0.94)$.

Foot length and chest circumference had the highest sensitivity (94\%) and specificity (90\%) respectively for screening low birth weight babies. A cut-off of foot length $7.9 \mathrm{~cm}$ had sensitivity of $94 \%$ and specificity of $83 \%$ for predicting low birth weight. Cut off for $\mathrm{CC}$ was $31.0 \mathrm{~cm}$ in their study [18].

Similar results were obtained in our study with FL having higher AUC (0.982) as compared to $\mathrm{CHC}$ with sensitivity of $97.83 \%$ and specificity of $87.97 \%$ for predicting $<2.5 \mathrm{~kg}$. The cutoff of FL in our study was $7.3 \mathrm{~cm}$ and the cutoff of $\mathrm{CHC}$ was $28.5 \mathrm{~cm}$ for predicting LBW. A hospital-based study done in Udaipur, India also found that foot length less than $7.2 \mathrm{~cm}$ was the cutoff to identify LBW babies ( $<2500 \mathrm{gm})$ [9].

However LC Mullany et al. concluded that compared to the use of foot length, classification rules based on chest circumference measures were more sensitive and specific for identifying LBW infants [8]. Another study done by Dhananjay B et al, found the highest correlation of birth weight with chest circumference $(r=$ 0.70 ). and also, maximum sensitivity of detecting low birth weight was seen with chest circumference (94.26\%) [19]. The cut off for CHC in Nepal was 30.8 $\mathrm{cm}$ and in Iran it was $31.2 \mathrm{~cm}[21,22]$.

One Indian study done by Satarupa Mukherjee et al. (2013) at Kolkata found that for identification of LBW babies (<2500 gm), foot length less than $7.85 \mathrm{~cm}$ had $100 \%$ sensitivity and $95.3 \%$ specificity. Foot length less than $6.85 \mathrm{~cm}$ had $100 \%$ sensitivity and $94.9 \%$ specificity for identification of VLBW babies $(<1500$ $\mathrm{gm})$. However, the cut off for VLBW was $6.4 \mathrm{~cm}$ in our study with sensitivity of $89.4 \%$ and specificity of $91.2 \%$ [23].

A similar study done by Hirve et al. with 89 babies in Pune, India had found foot length less than $6.3 \mathrm{~cm}$ for VLBW babies with a sensitivity of $100 \%$ and specificity of $95.2 \%$. They had devised a tri-colour foot tape for use at home by the neonatal caretaker i.e. mother or birth attendant [7].
We also found that FL can also be a surrogate marker to predict pre-term delivery. The optimal cutoff was FL $<=7.1 \mathrm{~cm}$ to classify as Pre-term. ROC curve analysis showed AUC $=0.962$ with $91 \%$ sensitivity and 90\% specificity. This was however different from similar study done by S. Mukhrjee et al where Foot length $<8$ $\mathrm{cm}$ was $93.5 \%$ sensitive and $75.3 \%$ specific for preterm identification [23].

Similar to our study, Anshuman Srivastava et al. (2015) found that gestational age and foot length also showed a positive correlation with a correlation coefficient of 0.99 and Foot length of $7.37 \mathrm{~cm}$ can be used as a cutoff point for differentiating between term and preterm babies [25].

The strength of our study was the large sample size. However, the limitation was that we did all measurements within 24 hrs of life and we did not test the usefulness of these measures after day 1 in identifying LBW or gestational age.

A study in Uganda however showed that $\mathrm{HC}$ and $\mathrm{CHC}$ could be measured in the first 2 weeks of life and extrapolated to estimate the measurements at the day of birth [26].

\section{Conclusion}

We concluded that both foot length and chest circumference can be used as predictors for birth weight and gestational age estimation but foot length was more appropriate than chest circumference, because of its high predictive value and ease of measurement without increasing the risk of exposure and infection. FL $<=$ $6.4 \mathrm{~cm}$ predicts VLBW; between $6.4 \mathrm{~cm}$ to $7.3 \mathrm{~cm}$ predicts LBW and $>7.3 \mathrm{~cm}$ predicts NBW. For estimating preterm birth FL cut off was $<=7.1 \mathrm{~cm}$. Screening of babies which are in need of extra care can be done using our cut off values and this can help in reducing neonatal mortality by early referral of preterm and VLBW babies

What is already known- Various anthropometric parameters like foot length and chest circumference, can be used to predict birth weight of newborn babies, however the cut off varies between different geographical areas.

What this study adds- Foot length is more sensitive and specific than chest circumference in predicting birth weight and gestational age of newborn babies and the cut offs described in our study can be used in south India. 


\section{Contribution by authors}

1. Dr. P. Sudha Priya -formed the concept of study and data collection.

2. Dr. Rinu Dwivedi - Manuscript writing, helped in data collection.

3. Dr. Anushadipti -helped in data collection.

4. Prof K.V.S. Sarma - statistical analysis.

Funding: Nil, Conflict of interest: None initiated, Perission from IRB: Yes

\section{References}

1. Lawn JE, Cousens S, Zupan J; et al. 4 million neonatal deaths: when? Where? Why? Lancet. 2005 Mar 5-11;365(9462): 891-900. DOI:10.1016/S0140$6736(05) 71048-5$.

2. Sankar MJ, Neogi SB, Sharma J, et al. State of newborn health in India. Journal of Perinatology. 2016;36 (Suppl 3): S3-S8. doi: 10.1038/jp. 2016. 183.

3. Lawn JE, Kerber K, Enweronu-Laryea C, et al. Newborn survival in low resource settings--are we delivering? BJOG. 2009 Oct;116 Suppl 1:49-59. doi: 10.1111/j.1471-0528.2009.02328.x.

4.Baqui AH, Ahmed S, El Arifeen S, et al. Effect of timing of first postnatal care home visit on neonatal mortality in Bangladesh: a observational cohort study. BMJ. 2009 Aug 14; 339: b2826. doi: 10. 1136/bmj. b2826

5. James DK, Dryburgh EH, Chiswick ML. Foot length-a new and potentially useful measurement in the neonate. Arch Dis Child. 1979 Mar; 54 (3): 22630 .

6. Daga SR, Daga AS, Patole S, et al. Foot length measurement from foot print for identifying a newborn at risk. J Trop Pediatr. 1988 Feb;34(1):16-9. doi: 10. 1093/tropej/34.1.16.

7. Hirve SS, Ganatra BR. Foot tape measure for identification of low birth weight newborns. Indian Pediatr. 1993 Jan;30(1):25-9.

8. Mullany LC, Darmstadt GL, Khatry SK, et al. Relationship between the surrogate anthropometric measures, foot length and chest circumference and birth weight among newborns of Sarlahi, Nepal. Eur J Clin Nutr. 2007 Jan;61(1):40-6. Epub 2006 Aug 2.
9. Mathur A, Tak SK, Kothari P. 'Foot length'--a newer approach in neonatal anthropometry.J Trop Pediatr. 1984Dec;30(6): 333-6.doi:10.1093/ tropej/30.6.333.

10.Marchant T, Jaribu J, Penfold S, et al. Measuring newborn foot length to identify small babies in need of extra care: a cross sectional hospital based study with community follow-up in Tanzania. BMC Public Health. 2010 Oct 19;10:624. doi: 10.1186/1471-245810-624.

11. Das JC, Afroze A, Khanam ST, et al. Mid-arm circumference: an alternative measure for screening low birth weight babies. Bangladesh Med Res Counc Bull. 2005 Apr;31(1):1-6.

12. Sharma JN, Saxena S, Sharma U. Thigh circumference at birth as the best predictor of low birth weight babies. Indian Pediatr. 1989 Jan;26(1):18-21.

13. Kadam YR, Somaiya P, Kakade SV: A study of surrogate parameters of birth weight. Indian $\mathbf{J}$ Community Med 2005, 30(3):89-91.doi: 10.4103/09700218.42857

14. Vishnu Datt Pandey, Vishram Singh , G L Nigam , Yasmeen Usmani, Yogesh Yadav: Fetal Foot Length for Assessment of Gestational Age: A Comprehensive Study in North India. Sch. J. App. Med. Sci., 2015; 3 (1C):139-144

15. Mhaskar R Agarwal, N Takkar, D Buckshee, K Anandalakshmi, and Deorari A. Fetal foot length- a new parameter for assessment of gestational age. International Journal of Gynecology \& Obstetrics, 1989; 29: 35-38. doi: 10.1016/ 0020-7292 (89)90 $126-4$

16. Mercer BM, Sklar S, Shariatmadar A, et al. Fetal foot length as a predictor of gestational age. Am J Obstet Gynecol. 1987 Feb;156(2):350-5.

17. Kulkarni ML, Rehman M Neonatal assessment beyond birth weight, Indian Pediatr, 1991, vol. 28 (pg. 929-31)

18. Elizabeth NL, Christopher OG, Patrick K. Determining an anthropometric surrogate measure for identifying low birth weight babies in Uganda: a hospital-based cross sectional study. BMC Pediatr. 2013 Apr 12; 13: 54. doi: 10.1186/ 1471- 243113-54. 
19. Dhananjay B. NaikA. P. KulkarniN. R. Aswar. Birth weight and anthropometry of newborns. The Indian Journal of Pediatrics. 2003;70(2):145-146

20. Taksande A, Vilhekar KY, Chaturvedi P, et al. Predictor of low birth weight babies by anthropometry. J Trop Pediatr. 2007 Dec;53(6):420-3. Epub 2007 Jun 15. DOI:10.1093/tropej/fmm052

21. Sajjadian N, Shajari H, Rahimi F, Jahadi R, Barakat MG. Anthropometric measurements at birth as predictors of low birth weight. Health. 2011;3(12):752756. doi: 10.4236/health.2011.312125.

22. Sreeramareddy CT, Chuni N, Patil R, et al. Anthropometric surrogates to identify low birth weight Nepalese newborns: a hospital-based study. BMC Pediatr.2008 Apr 25;8:16. doi: 10.1186/1471-2431-8-16
23. Satarupa Mukherjee, Prithwish Roy: Measuring New Born Foot Length to Identify Small Babies in Need of Extra Care:a Cross-Sectional Hospital Based Study. Iran J Pediatr 2013;23(5): 508-512.

24. Ballard JL, Khoury JC, Wedig K, et al. New Ballard Score, expanded to include extremely premature infants. J Pediatr. 1991 Sep;119(3):417-23.

25. Anshuman Srivastava, Utkarsh Sharma, Sumit Kumar.To study correlation of foot length and gestational age of new born by new Ballard score; Int J Res Med Sci. 2015 Nov;3(11):3119-3122DOI: http: //dx. doi.org /10.18203/2320-6012.ijrms20151147

26. Wabwire-Mangen F, Kigozi G, Gray RH. Estimation of birth weight and gestational age during the first two weeks of life among home deliveries. Int $\mathrm{J}$ Gynaecol Obstet. 2002 Dec;79(3):255-7.

\section{How to cite this article?}

P.Sudhapriya, Rinu Dwivedi, Anushadipti, Sarma K.V.S. Anthropometric measurements- a study on options for identification of small babies in need of extra care. Int J Pediatr Res. 2019;6(01):35-41.doi:10.17511/ijpr.2019.i01.06 